\title{
Numerical Modeling of 3-D Environmental Variability
}

\author{
Kevin B. Smith \\ Code PH/Sk, Department of Physics \\ Naval Postgraduate School \\ Monterey, CA 93943 \\ phone: (831) 656-2107 fax: (831) 656-2084 email: kbsmith@nps.edu
}

Award \#: N0001412WX20272

\section{LONG-TERM GOALS}

The goals of this work were multi-faceted, consistent with the various efforts supported by this work. Particular focus was placed on analysis of the scattering from rough ocean surfaces and comparison with experimental data. In collaboration with Prof. Mohsen Badiey of the University of Delaware, modeling efforts were expanded to include dynamic rough surface interface and near-surface bubble scattering. By continuing to expand and improve the capabilities of the numerical modeling methods, the long-term goal of this effort is to provide a useful tool for understanding the physical phenomena leading to variability in the acoustic propagation.

\section{OBJECTIVES}

The overall objective of this work was to study the response of the acoustic field in the presence of environmental variability, and to examine the relative effects of rough surfaces, volumetric perturbations (e.g., nonlinear internal waves, near-surface bubbles), and bottom topography.

\section{APPROACH}

This work continued and expanded upon previous efforts to study the effects of environmental variability on the 3-D structure of the total acoustic field (pressure, particle velocity, acoustic intensity, etc). In FY11, a 3-D version of the MMPE model was employed by Georges Dossot at URI (advised by Prof. J. Miller) and Joseph Senne at UDel (advised by Prof. M. Badiey) to show similar trends in signal intensity due to the passage of non-linear internal wave as measured in SW06 data. Additional work with UDel was performed with a 2-D version of MMPE that included scattering from a rough ocean surface, and results were compared with data from the KAM08 data. Both levels and signal spread showed good agreement. At the end of FY11, the theoretical framework was developed to perform 3-D calculations of scattering from a 2-D rough surface interface.

MMPE modeling efforts were expanded in FY12 to include 2-D scattering from dynamic rough ocean interfaces and other features such as near-surface bubbles. This work was conducted in part to support the $\mathrm{PhD}$ research of Joseph Senne (UDel). 


\section{Report Documentation Page}

Form Approved

OMB No. 0704-0188

Public reporting burden for the collection of information is estimated to average 1 hour per response, including the time for reviewing instructions, searching existing data sources, gathering and maintaining the data needed, and completing and reviewing the collection of information. Send comments regarding this burden estimate or any other aspect of this collection of information,

including suggestions for reducing this burden, to Washington Headquarters Services, Directorate for Information Operations and Reports, 1215 Jefferson Davis Highway, Suite 1204, Arlington

VA 22202-4302. Respondents should be aware that notwithstanding any other provision of law, no person shall be subject to a penalty for failing to comply with a collection of information if it

does not display a currently valid OMB control number.

\begin{tabular}{|c|c|c|}
\hline $\begin{array}{l}\text { 1. REPORT DATE } \\
\mathbf{2 0 1 2}\end{array}$ & $\begin{array}{l}\text { 2. REPORT TYPE } \\
\text { N/A }\end{array}$ & $\begin{array}{l}\text { 3. DATES COVERED } \\
\text { - }\end{array}$ \\
\hline \multirow{3}{*}{\multicolumn{2}{|c|}{$\begin{array}{l}\text { Numerical Modeling of 3-D Environmental Variability } \\
\text { Numb }\end{array}$}} & 5a. CONTRACT NUMBER \\
\hline & & 5b. GRANT NUMBER \\
\hline & & 5c. PROGRAM ELEMENT NUMBER \\
\hline \multirow{3}{*}{\multicolumn{2}{|c|}{ 6. AUTHOR(S) }} & 5d. PROJECT NUMBER \\
\hline & & 5e. TASK NUMBER \\
\hline & & 5f. WORK UNIT NUMBER \\
\hline \multicolumn{2}{|c|}{$\begin{array}{l}\text { 7. PERFORMING ORGANIZATION NAME(S) AND ADDRESS(ES) } \\
\text { Code PH/Sk, Department of Physics Naval Postgraduate School } \\
\text { Monterey, CA } 93943\end{array}$} & $\begin{array}{l}\text { 8. PERFORMING ORGANIZATION } \\
\text { REPORT NUMBER }\end{array}$ \\
\hline \multirow{2}{*}{\multicolumn{2}{|c|}{ 9. SPONSORING/MONITORING AGENCY NAME(S) AND ADDRESS(ES) }} & 10. SPONSOR/MONITOR'S ACRONYM(S) \\
\hline & & $\begin{array}{l}\text { 11. SPONSOR/MONITOR'S REPORT } \\
\text { NUMBER(S) }\end{array}$ \\
\hline
\end{tabular}

12. DISTRIBUTION/AVAILABILITY STATEMENT

Approved for public release, distribution unlimited

13. SUPPLEMENTARY NOTES

The original document contains color images.

14. ABSTRACT

15. SUBJECT TERMS

16. SECURITY CLASSIFICATION OF:

a. REPORT

unclassified b. ABSTRACT

unclassified
17. LIMITATION OF ABSTRACT

SAR
18. NUMBER

OF PAGES

10 19a. NAME OF RESPONSIBLE PERSON unclassified 
Additional work was also conducted to support the PhD research of Huikwan Kim at Univ of Rhode Island (in collaboration with Prof. Jim Miller and Prof. Gopu Potty), in which the MMPE model was expanded to include acoustic propagation in an atmospheric layer over the ocean surface. This version of the model is being employed to investigate noise propagation from off-shore wind turbine installations.

Finally, work progressed to extend the 3-D MMPE model for 2-D rough surface scattering to Cartesian coordinates.

\section{WORK COMPLETED}

Utilizing a 2-dimensional (range and depth) version of the MMPE model that accounts for rough surface scattering, adapted for use in FY11, the effects of a dynamically evolving rough ocean surface were investigated. The rough surface was modeled after data collected during the KAM11 experiment by Mohsen Badiey at the Univ of Delaware and collaborators. Recorded data at near-bottom receiver stations exhibited deterministic scattering structures in the arrival patterns. The MMPE model was then utilized to confirm the predictability of some aspects of these signals.

In addition, a version of the MMPE model was updated in FY12 to include the effects of near-surface bubbles. This was done by incorporating a model of near-surface bubble plume effects on sound speed and attenuation, developed by Joseph Senne at the Univ of Delaware, under the supervision of Prof. Mohsen Badiey. The model was 2-dimensional (range and depth), and was correlated with a 1dimensional rough surface model, previously incorporated into MMPE. With the addition of the nearsurface bubbles effects, the influence of near-surface bubbles on the scattering statistics was examined.

A new version of the 2-D MMPE model was also implemented in FY12 that accounts for propagation in the air above the ocean surface. While this also has potential for future surface scattering studies, it was utilized in FY12 by Huikwan Kim at Univ of Rhode Island, under the supervision of Profs. Jim Miller and Gopu Potty. The model was further adapted to incorporate modeled noise fields from the installation of off-shore wind turbines, generated by an FE model, and initial estimates of the propagation of these acoustic fields in the air, water, and sediment were computed.

In FY11, the analytical expressions for modeling a 2-dimensional rough ocean surface with a 3dimensional version of MMPE were developed and implemented in cylindrical coordinates. In FY12, this was extended to include the expressions consistent with a Cartesian coordinate system, and implementation into a new version of MMPE is underway. 


\section{RESULTS}

\section{Dynamic Rough Ocean Surface and Near-Surface Bubble Studies:}

A schematic of the KAM11 experimental geometry for the UDel study is provided in Fig. 1 (courtesy of Mohsen Badiey). A pair of UDel tripods were deployed on the seafloor, each with a source and an eight-element receiving array for reciprocal transmissions. There was also a UDel waverider buoy approximately half-way between the tripods to record the rough surface conditions. Figure 1 also displays a top view of geometry, the sound speed profile measured by a nearby thermistor string, and a sample measured surface wave spectrum.

During the time of the recorded surface wave spectrum, reciprocal transmissions were recorded on each tripod, and on monitoring hydrophones near the ocean surface at the top of the thermistor string.

Figure 2 displays the impulse responses received over the course of $30 \mathrm{~s}$ for these reciprocal transmissions at both shallow and deep depths. The data exhibited some interesting coherently focused surface structures, presumably due to large-scale surface wave focusing. The goal of the MMPE modeling was, therefore, to incorporate the measured surface wave roughness spectra and compute the predicted impulse response to determine if these structures were, indeed, predictable.

In Fig. 3, the MMPE results are presented. As anticipated, many similar deterministic features appear in the arrival structure, especially at the mid-range between the tripods. The results are more dissimilar at the farther range of the tripods themselves, and we are currently investigating influences that could be impacting these results.
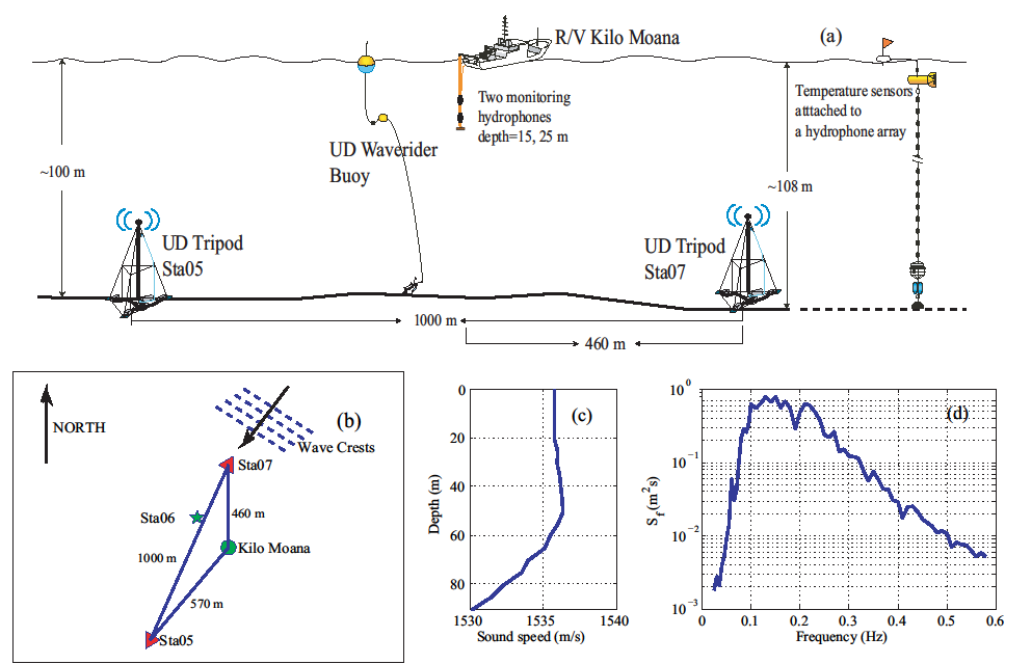

Figure 1: KAM11 experiment. (a) Schematics of the experiment. (b) Top view of source-receiver position, surface waverider buoy, and monitoring hydrophones tethered to $R / V$ Kilo Moana, with respect to the surface wave propagation. (c) Measured sound speed profile. (d) Measured surface wave spectrum. [From Badiey, et al, JASA 132, EL290-295.] 
In Fig. 4, a realization of the sound speed perturbation near the surface in the presence of bubble plumes is presented (courtesy of Joseph Senne). This perturbation was incorporated into the existing 2-D MMPE model with rough surface scattering in order to explore the additional effects, if any, of near-surface bubbles. Figure 5 displays the TL structure for various numerical scenarios, i.e. with no bubble effects included, with bubble effects included, and with a simplified bubble effect included. Obvious differences occur depending upon how the effect of the near-surface bubble layer is treated.
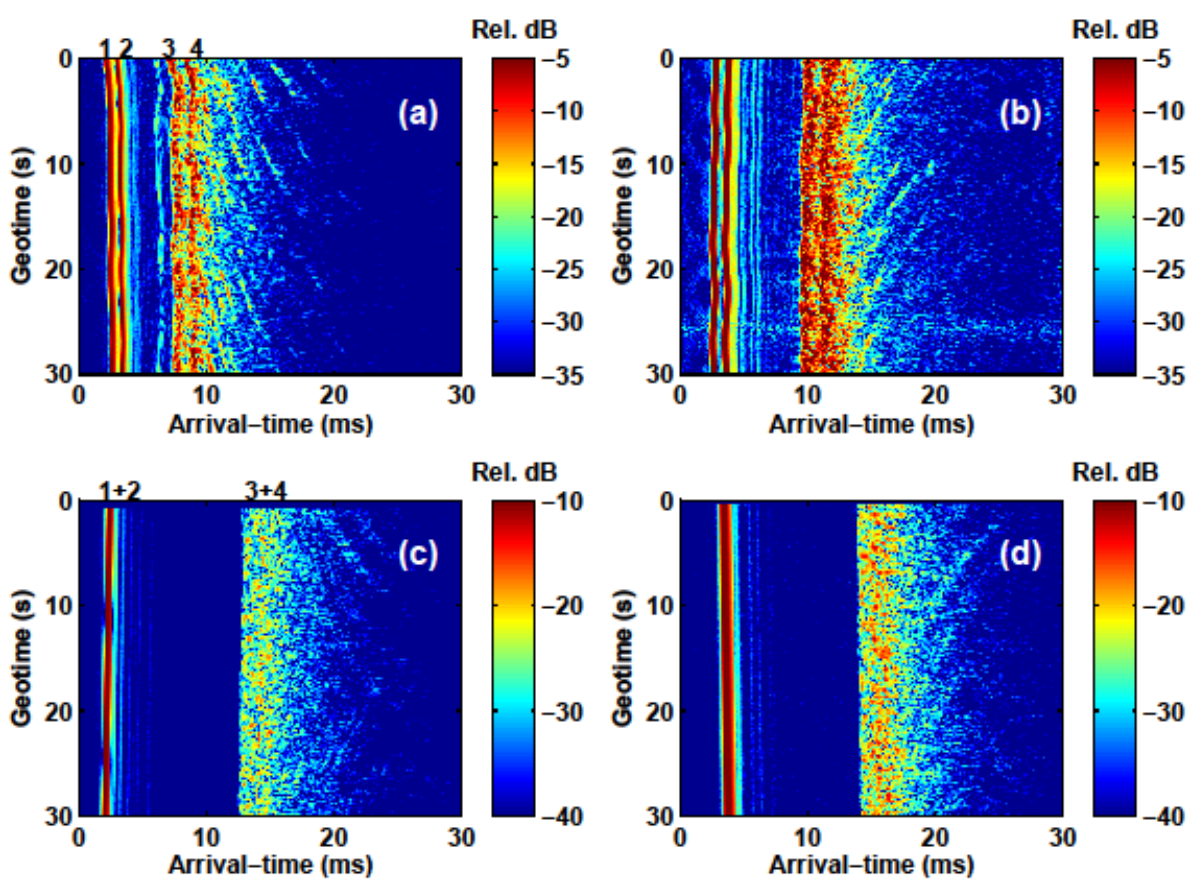

Figure 2: Measured impulse responses at the monitoring hydrophone and two acoustic stations during the reciprocal transmissions. (a) St05-Kilo Moana track (range $=460 \mathrm{~m}$; angle $=12^{\circ}$ ), (b) St07Kilo Moana track (range $=460 \mathrm{~m}$; angle $\left.=42^{\circ}\right)$, (c) Sta05-Sta07 track $\left(\right.$ range $=1000 \mathrm{~m}$, angle $\left.=27^{\circ}\right),($ d) Sta07-Sta05 track (range $=1000 \mathrm{~m}$, angle $\left.=27^{\circ}\right)$. [From Badiey, et al, JASA 132, EL290-295.] 

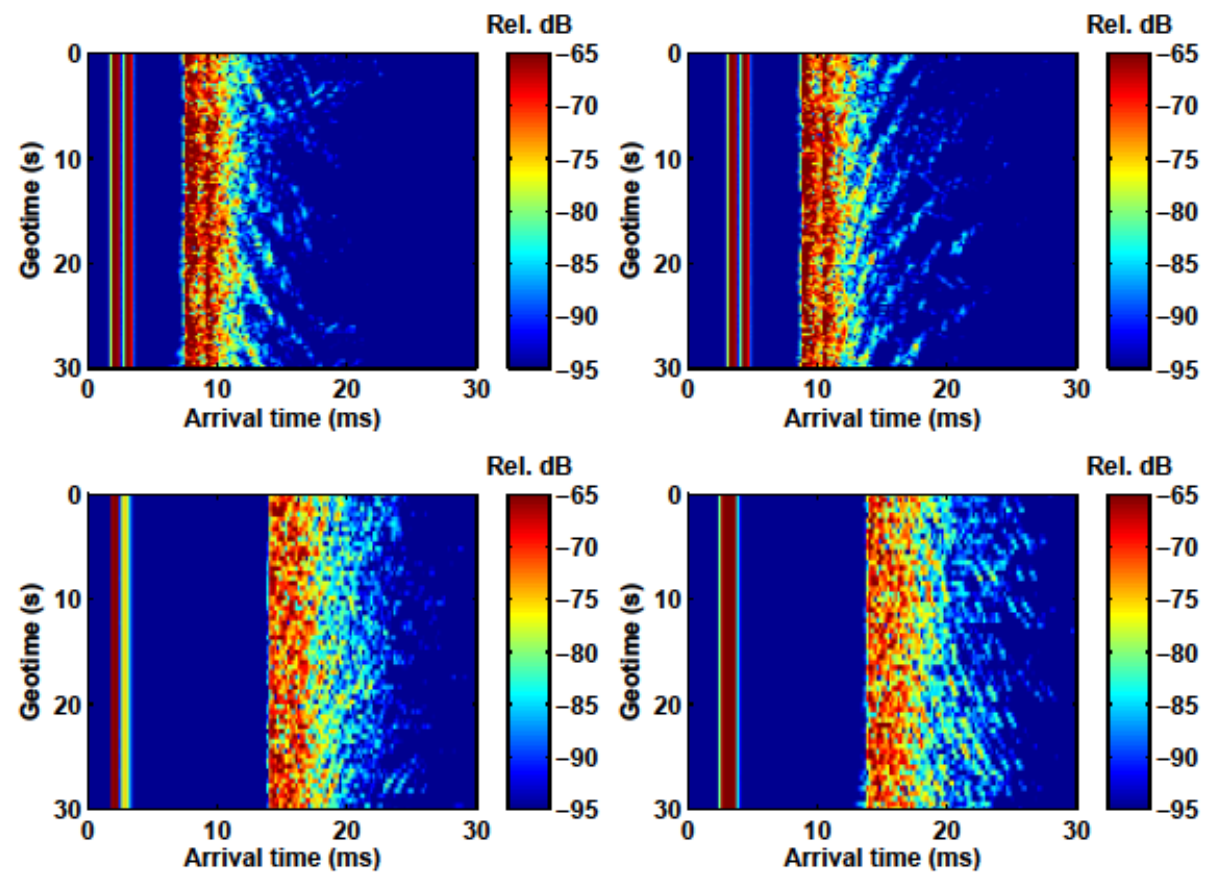

Figure 3: Same as Fig. 2, but modeled impulse responses. [From Badiey, et al, JASA 132, EL290-295.]

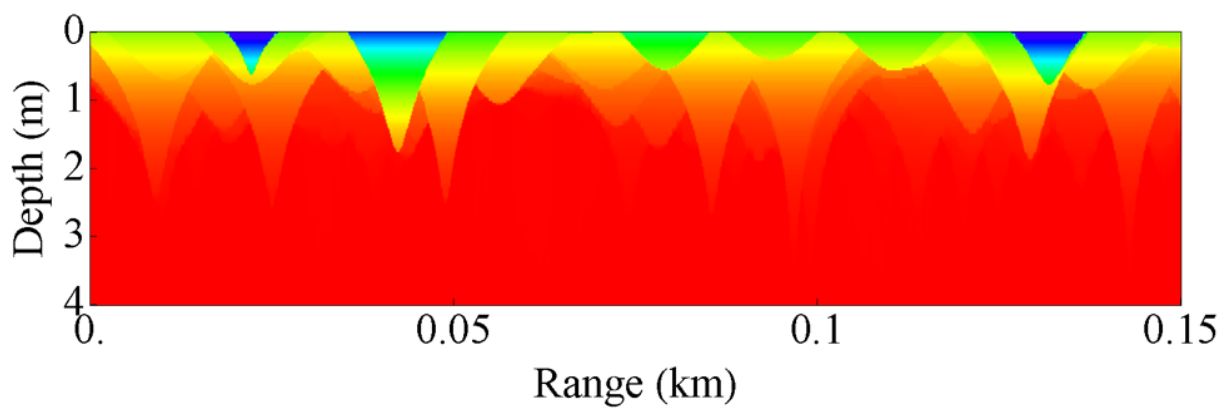

Figure 4: Modeled sound speed as a function of range and depth. [From Senne PhD Dissertation.] 
(a)

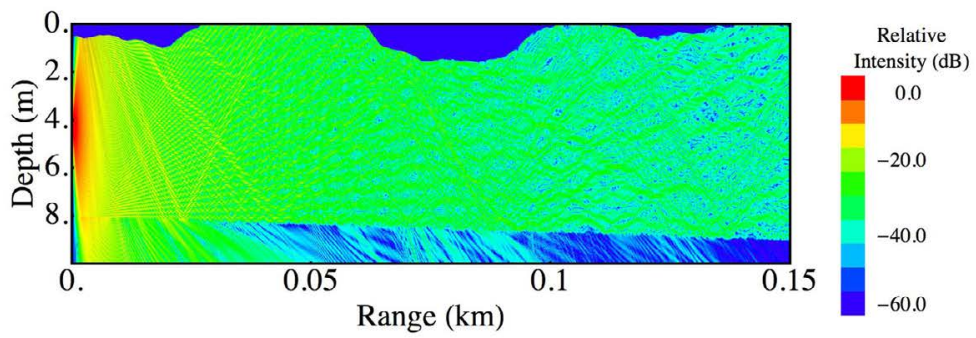

(b)

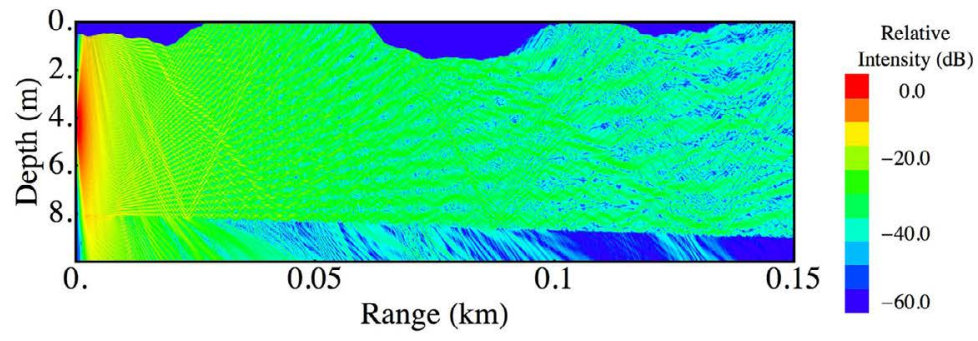

(c)

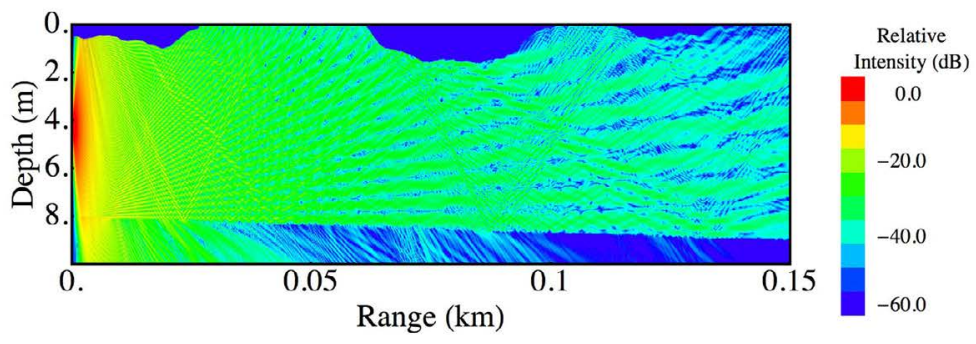

Figure 5: Intensity as a function of range and depth for single frequency runs computed at $20 \mathrm{kHz}$ using RS PE with (a) no bubbles, (b) the range-dependent bubble model, and (c) the rangeindependent bubble model. [From Senne PhD Dissertation.]

In Fig. 6, some detailed analysis of the relative surface scattered acoustic intensity for the different near-surface bubble effects is displayed. These results are consistent with the effects of near-surface bubbles being much more pronounced for scattering near the specular point. 
(a)

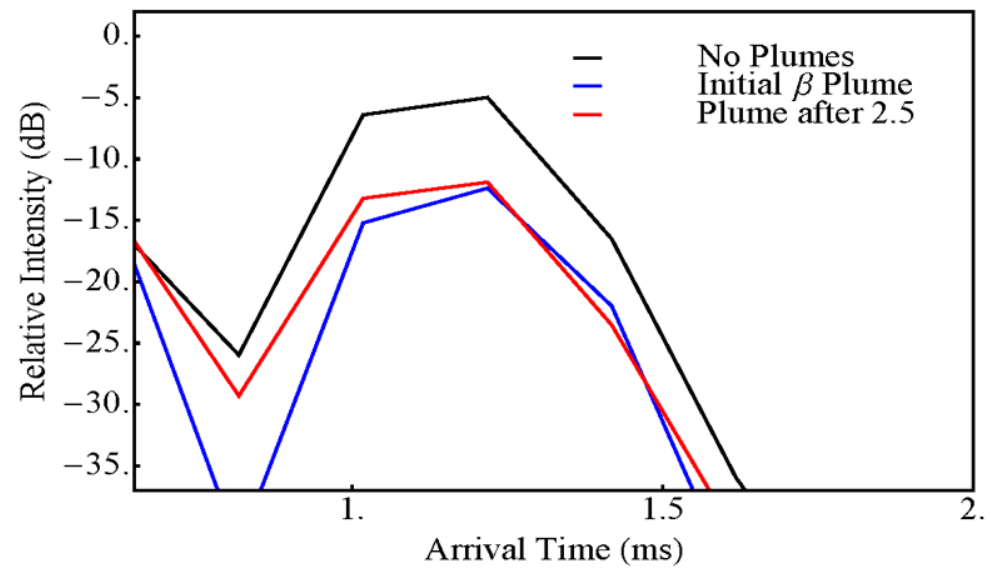

(b)

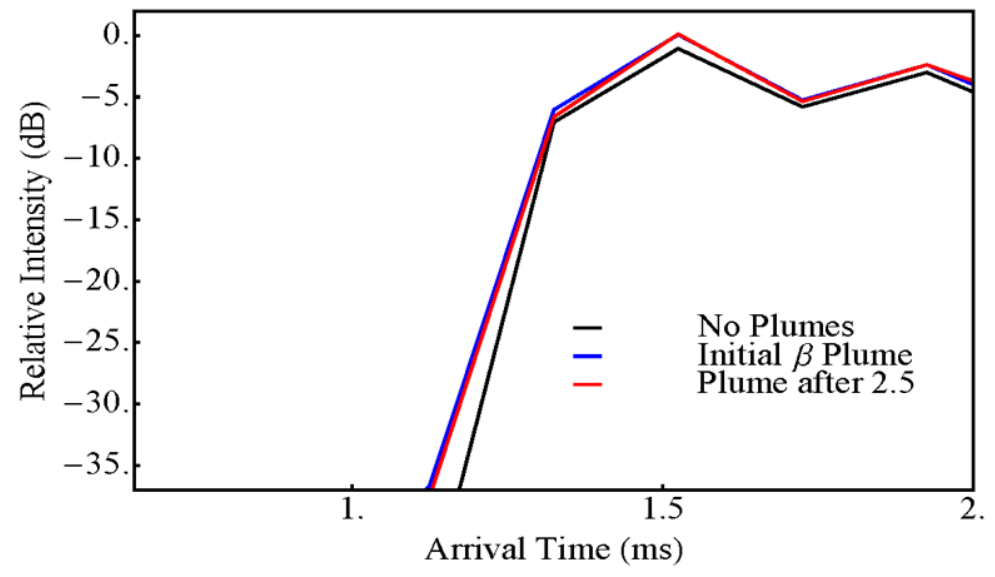

Figure 6: Modeled acoustic intensity as a function of arrival time. Results were generated using a flat sea surface with a single evolving bubble plume. Returns from acoustic paths that reflect from the surface (a) near the specular point and (b) away from the specular point. [From Senne PhD Dissertation.]

Propagation in Air, Water, and Sediment Studies:

A new version of MMPE was developed in FY12 that includes acoustic propagation above the sea surface. The surface is now treated as a boundary between two contrasting media, much the way the water/bottom interface has been treated. This version still needs validation, but was used to generate some initial results for propagation of the noise field due to off-shore wind turbine installation.

Figure 7 displays initial results of the 3-layer MMPE model. The source was generated based on an FE model of the pile-driving that takes place for wind turbine installations. The development of this model provides a tool for future studies that need to capture a more complete picture of acoustic propagation in and around the ocean medium. 

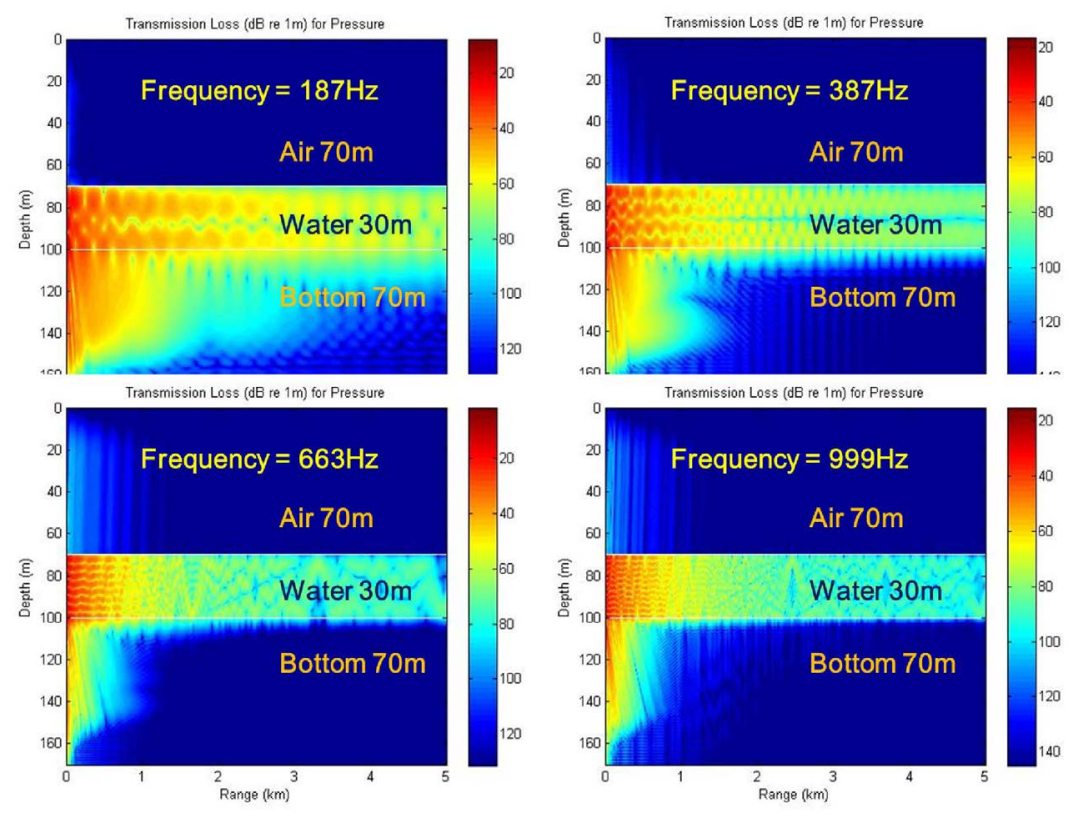

Figure 7: TL calculations for four different frequency starting fields based on modeled source field from wind turbine installation. [From Kim, et al, Oceans 2012.]

\section{3-D Rough Surface Scattering Studies:}

In FY11, the field equations corresponding to the displaced surface field transformation for rough surface scattering were derived in 3-D cylindrical coordinates. While some initial results were computed and showed some expected effects, it was determined that expressions based on a Cartesian coordinate system might be more useful in many circumstance. These derivations were performed but not yet published or tested. The form of these transformed equations in Cartesian coordinates were shown to be

$$
\frac{\partial \tilde{\psi}}{\partial x}=-i k_{0}\left(\tilde{T}_{o p}+\tilde{U}_{o p}\right) \tilde{\psi}
$$

where the operators

$$
\tilde{T}_{o p}=\left\{\begin{array}{c}
T_{3 D}, \quad z>\eta(x, y) \\
T_{3 D}+\frac{i 2}{k_{0}}\left[\frac{\partial^{2} \eta}{\partial x \partial y}(z-\eta)-\frac{\partial \eta}{\partial x} \frac{\partial \eta}{\partial y}\right] \frac{\partial}{\partial y}, z<\eta(x, y)
\end{array},\right.
$$

and 


$$
\tilde{U}_{o p}=\left\{\begin{array}{cc}
U_{3 D}(x, y, z) & , z>\eta(x, y) \\
U_{3 D}(x, y,-z+2 \eta(x, y))-2 \frac{\partial^{2} \eta}{\partial x^{2}}(z-\eta) & , z<\eta(x, y) \\
+\frac{i}{k_{0}}\left[\frac{\partial^{3} \eta}{\partial x \partial y^{2}}(z-\eta)-2 \frac{\partial^{2} \eta}{\partial x \partial y} \frac{\partial \eta}{\partial y}-\frac{\partial \eta}{\partial x} \frac{\partial^{2} \eta}{\partial y^{2}}-i 2 k_{0}\left(\frac{\partial^{2} \eta}{\partial x \partial y}(z-\eta)-\frac{\partial \eta}{\partial x} \frac{\partial \eta}{\partial y}\right)^{2}\right]
\end{array}\right.
$$

and the surface boundary is defined at depth $z=\eta(r, \phi)$. The form of the operator $\tilde{T}_{o p}$ presents some challenges in implementation due to the additional differential term that must be applied over a variable rough surface. A scheme has been developed to address this and is currently being implemented in a new 3-D rough surface version of MMPE.

\section{IMPACT/APPLICATIONS}

The impact of the work done on modeling the 2-D propagation effects due to rough surface scattering is to provide a tool for future use in the development of acoustic communication algorithms and testing. The comparison with measured data also suggests it can be used to predict certain deterministic arrival structures.

The impact of the work done on extending the surface scattering model to 3-D is to allow researchers in future models to directly compute the 3-D, out-of-plane scattering effects of the sea surface. This could also be applied to the development of acoustic communication algorithms, or possibly be utilized to study the effects on high-frequency sonar systems.

The studies of the propagation in air/water/sediment will allow researchers to investigate the impact of off-shore, noise-generating platforms on ambient noise both above and below the sea surface. It may also be used to compare with 2-D surface scattering models based on field transformation techniques.

\section{RELATED PROJECTS}

The rough surface scattering work, both 2-D and 3-D, are on-going efforts done in collaboration with Dr. Mohsen Badiey and his colleagues at the Univ. of Delaware. This work is expected to continue in FY13. The work on propagation in air/water/sediment is an on-going effort with colleagues at the Univ. of Rhode Island, and is expected to continue in FY13. In addition, some of the previous work done with MMPE to model rough bottom effects will be expanded in FY13 into a collaboration with Prof. Harry Deferrari and colleagues at the Univ. of Miami.

\section{REFERENCES}

1. Senne, J., "Modeling of Acoustic Propagation for High Frequency Transmissions Under Variable Sea Surfaces," University of Delaware Dissertation, 2012. 


\section{PUBLICATIONS}

2. Badiey, M., Song, A., and Smith, K.B., "Coherent reflection from surface gravity water waves during reciprocal acoustic transmissions," J. Acoust. Soc. Am. 132, pp. EL290-295, 2012.

3. Senne, J., Song, A., Badiey, M., and Smith, K.B., "Parabolic equation modeling of high frequency acoustic transmission with an evolving sea surface," J. Acoust. Soc. Am. 132, pp. 1311-1318, 2012.

4. Barton, R.J., Moss, G.R., and Smith, K.B., "A comprehensive examination of the acoustic vector fields scattered by cylindrical bodies,” J. Acoust. Soc. Am. 132, pg. 1985, 2012.

5. Smith, K.B., "Field transformational approach to three-dimensional scattering from twodimensional rough surfaces," J. Acoust. Soc. Am. 131, pp. EL441-447, 2012.

6. Kim, H., Potty, G., Dossot, G., Smith, K.B., and Miller, J.H., "Long range propagation modeling of offshore wind turbine construction noise using Finite Element and Parabolic Equation models," Proc. Oceans2012, 21-24 May, Yeosu, Korea, 2012.

7. Kim, H., Potty, G., Miller, J.H., Smith, K.B., and, Dossot, G. "Long range propagation modeling of offshore wind turbine construction noise using Finite Element and Parabolic Equation models," J. Acoust. Soc. Am. 131, pg. 3392, 2012.

8. Barton, R.J., Moss, G.R., and Smith, K.B., "Characterization of scattered acoustic intensity fields of finite cylinders in the resonance region," J. Acoust. Soc. Am. 130, pg. 2332, 2011.

9. Song, A., Senne, J., Badiey, M., and Smith, K.B., "Underwater acoustic communication channel simulation using parabolic equation,” J. Acoust. Soc. Am. 130, pg. 2347, 2011.

10. Smith, K.B., Badiey, M., and Senne, J., "Three-dimensional surface scattering using a parabolic equation model,” J. Acoust. Soc. Am. 130, pg. 2348, 2011.

11. Senne, J., Song, A., Smith, K.B., and Badiey, M., "An investigation of the effects of rough seas and bubble injections on high frequency propagation using a parabolic equation method," J. Acoust. Soc. Am. 130, pg. 2530, 2011.

12. Barton, R.J., Dossot, G.A., and Smith, K.B., "Variations in the active and reactive intensity components of the sound field due to nonlinear internal waves," J. Acoust. Soc. Am. 130, pg. 2556, 2011. 